http://jmscr.igmpublication.org/home/

ISSN (e)-2347-176x ISSN (p) 2455-0450

crossref DOI: https://dx.doi.org/10.18535/jmscr/v7i10.150

Journal Of Medical Science And Clinical Research

IGM Publication

An Official Publication of IGM Publication

\title{
A Randomised Controlled Trial to Compare Preemptive Pregabalin with Gabapentin for Post-Operative Analgesia in Abdominal Hysterectomy
}

\author{
Authors \\ Arshid Ahmad Sofi ${ }^{1 *}$, Waqar-ul-Nisa ${ }^{2}$, Asif Abdullah ${ }^{3}$, Altaf Mir ${ }^{4}$ \\ ${ }^{1}$ Senior Resident, Department of Anesthesiology \& Critical Care, Govt. Medical College, Srinagar, India \\ ${ }^{2}$ Professor Department of Anesthesiology SKIMS Srinagar, India \\ ${ }^{3}$ Consultant Gynecology \& obstetrics, Health \& Medical Education, Srinagar, India \\ ${ }^{4}$ Senior Resident, Department of Anesthesiology SKIMS Srinagar, India \\ *Corresponding Author \\ Dr Arshid Ahmad Sofi
}

Senior Resident, Department of Anesthesiology \& Critical Care, Govt. Medical College, Srinagar, India

Abstract
Objectives: This study was designed to evaluate and compare the efficacy of a single preoperative dose
of pregabalin and gabapentin for attenuating postoperative pain and analgesic consumption after
abdominal hysterectomy.
Methods: 90 patients of ASA grade I or II were randomly allocated to three groups, with 30 patients in
each group. Patients in Group A were given Pregabalin 300mg, Group B were given Gabapentin $900 m g$
and Group C patients received placebo 1 hour prior to surgery. Postoperative pain was assessed by a
loomm visual analogue scale.
Results: Postoperative pain and postoperative analgesic consumption was reduced in the pregabalin and
gabapentin group compared with the placebo group $(P<0.05)$.
Conclusion: A single preoperative oral dose of Pregabalin 300 mg and Gabapentin $900 m g$ is an effective
method for reducing postoperative pain and analgesic consumption in patients undergoing elective
abdominal hysterectomy. Pregabalin is a better pre-emptive analgesic as compared to Gabapentin for
decreasing post-operative analgesic consumption.
Keywords: postoperative pain, pregabalin and gabapentin, abdominal hysterectomy, preoperative dose.

\section{Introduction}

Galen described pain as "A complex multidimensional human perception. It is divine to allay pain". ${ }^{1}$ Postoperative pain, regardless of its site, can adversely affect nearly every organ function, and so affects the post operative morbidity and mortality. Postoperative pain also affects recovery from surgery and anesthesia. Prevention and treatment of postoperative pain continues to be a major challenge in postoperative care and plays an important role in the early mobilization, shortened hospital stay, reduced hospital costs and well being of the surgical patients. ${ }^{2,3.4}$

Pre-emptive analgesia is defined as an antinociceptive treatment that prevents the establishment of altered central processing of afferent input, which amplifies postoperative pain. By decreasing the altered central sensory processing, preemptive analgesia is thought to 
consequently decrease the incidence of hyperalgesia and allodynia after surgery. A variety of interventions and medications have been used to achieve a pronounced pre-emptive effect, which includes the use of gabapentinoids ${ }^{5,6}$. Important gabapentinoids include gabapentin and pregabalin. Gabapentin and Pregabalin are structural analogues of GABA. Gabapentin was introduced in 1993 as an adjuvant anticonvulsant drug for the treatment of refractory partial seizures. ${ }^{7}$ More than 30 clinical trials evaluating the potential roles of gabapentin for post-operative analgesia, preoperative anxiolysis, prevention of chronic post surgical pain, attenuation of haemodynamic response to direct laryngoscopy and intubation, prevention of postoperative nausea and vomiting (PONV) and postoperative delirium have been published. ${ }^{8-16}$ Pregabalin has been found to be equally effective to gabapentin, however, at much lower doses. It has shown superior analgesic potency than gabapentin in rodent models of neuropathic pain. ${ }^{17,18}$

Abdominal hysterectomy is one of the most common gynecologic surgery that is associated with moderate to severe postoperative pain and requires multimodal analgesia. ${ }^{19}$ The analgesic effects of gabapentin and pregabalin have been investigated widely in surgical settings during the past few years.The findings of these trials suggest that gabapentin and pregabalin have analgesic effects in postoperative pain management. With this background in mind, we designed this study to compare pre-emptive Pregabalin with Gabapentin and placebo for post operative analgesia in abdominal hysterectomy.

\section{Methods}

This prospective, randomized, double-blind, and placebo controlled clinical study was designed to include 90 patients, ASA physical status I and II, undergoing elective abdominal hysterectomy for benign conditions under general anaesthesia. The study protocol was approved from the institutional ethical committee and written informed consent was obtained from all the patients. Patients having any known allergy to gabapentin or pregabalin, epilepsy, chronic pain syndrome, impaired renal function, any history of psychiatric disease and substance abuse were excluded from the study.

In Pre-anesthetic visit patients were familiarized with the use of a $100 \mathrm{~mm}$ linear VAS for pain and Sedation. Patients were randomly assigned to one of three study groups: Group A, B and C. Patients in group A received pregabalin $300 \mathrm{mg}$, Group B Patients received gabapentin $900 \mathrm{mg}$ and Patients in group $\mathrm{C}$ received placebo 1 hour before surgery. All the medications were identical, and administered orally, $1 \mathrm{~h}$ before the induction of anaesthesia with sips of water by a staff nurse who was not involved in the study.

Anaesthesia technique was standardized in all the groups. Patients were induced with propofol $2 \mathrm{mg} / \mathrm{kg}$, fentanyl 2 microgram $/ \mathrm{kg}$, orotracheal intubation was facilitated by atracurium $0.5 \mathrm{mg} / \mathrm{kg}$. Anesthesia was maintained using isoflurane (1 Mac) in combination with $\mathrm{N} 2 \mathrm{O} 50 \%$ and $\mathrm{O} 250 \%$ and intermittent atracurium when indicated. Intraoperative analgesia also included morphine $0.1 \mathrm{mg} / \mathrm{kg}$, used in all three groups. Intraoperative ondensetron $0.1 \mathrm{mg} / \mathrm{kg}$ was given before reversal. At the end of surgery, residual neuromuscular paralysis was antagonized with neostigmine 0.05 $\mathrm{mg} / \mathrm{kg}$ and glycopyrrolate $0.01 \mathrm{mg} / \mathrm{kg}$. After satisfactory recovery, the patients were extubated and shifted to the post-anaesthesia care unit (PACU) and assessed there for pain and sedation using VAS score $1 \mathrm{hr}$ after surgery. Rescue analgesia in PACU was given using IV tramadol $1 \mathrm{mg} / \mathrm{kg}$ and time to first analgesic request was noted, this was the time from the end of the surgery to the first registration of VAS score (1$10) \geq 3$. In the ward, postoperative pain was again assessed using VAS scores at 4, 8, 12 and 24 hours after surgery and analgesia was provided with i/v Paracetemol $15 \mathrm{mg} / \mathrm{kg}$.

Primary outcomes were severity of postoperative pain and postoperative analgesic requirement. Secondary outcomes were incidence of sideeffects such as postoperative nausea and vomiting 
(PONV), sedation, drowsiness and dizziness if any.

\section{Statistical Methods}

The recorded data was compiled and entered in a spreadsheet (Microsoft Excel) and then exported to data editor of SPSS Version 20.0 (SPSS Inc., Chicago, Illinois, USA). Statistical software SPSS (version 20.0) and Microsoft Excel were used to carry out the statistical analysis of data. Continuous variables were summarized in the form of means and standard deviations and categorical variables were summarized as percentages. Analysis of variance (ANOVA) was employed for inter group analysis of data and for multiple comparisons, least significant difference (LSD) test was applied. Chi-square test or Fisher's exact test, whichever appropriate, was used for comparison of categorical variables. Graphically the data was presented by bar and line diagrams. A P-value of less than 0.05 was considered statistically significant. All P-values were two tailed.

\section{Results}

A total of ninety patients were selected for the study and were randomly divided into three groups of thirty patients each. All the groups were comparable with respect to demographic characteristics like age, weight and duration of surgery. The mean age of patients was 50.7 years in Group A, 53.4 years in Group B, and 51.5 years in Group C. Mean weight of patients was $59.1 \mathrm{Kg}$ in Group A, $58 \mathrm{Kg}$ in Group B and $59.2 \mathrm{Kg}$ in Group C. Mean duration of surgery was 92.8 minutes in group A, 94.3 minutes in group B and 95 minutes in group $\mathrm{C}$. Comparison between the three groups with respect to age distribution, weight and duration of surgery was statistically insignificant $(P=0.171)[$ table 1$]$. Hemodynamic parameters like blood pressure, heart rate, oxygen saturation did not differ significantly among the groups.

Table1: Comparison of demographic profiles between the study groups

\begin{tabular}{|l|c|c|c|c|}
\hline Parameters & Group A & Group B & Group C & P value \\
\hline Age $(\mathrm{yrs})$ & $50.7 \pm 6.17$ & $53.4 \pm 5.13$ & $51.5 \pm 5.76$ & 0.171 \\
\hline Height $(\mathrm{cm})$ & & & & \\
\hline Weight $(\mathrm{kg})$ & $59.1 \pm 6.54$ & $58 \pm 6.13$ & $59.2 \pm 6.44$ & 0.749 \\
\hline ASAI/II & $21 / 9$ & $18 / 12$ & $22 / 8$ & 0.516 \\
\hline Duration of surgery & $92.8 \pm 4.58$ & $94.3 \pm 4.39$ & $95 \pm 5.19$ & 0.198 \\
\hline
\end{tabular}

Postoperative pain scores using VAS showed groups $(\mathrm{P}<0.05)$ with Pregabalin group having the statistically significant difference among the three least VAS scores for pain (Mean \pm SD).

Table 2: Comparison of pain scores using VAS among the study groups.

\begin{tabular}{|l|c|c|c|c|}
\hline Time Interval & Group A & Group B & Group C & P value \\
\hline $\mathrm{I} \mathrm{hr}$ & $2.77 \pm 1.194$ & $3.63 \pm 1.732$ & $4.93 \pm 1.874$ & $<0.001^{*}$ \\
\hline $4 \mathrm{hrs}$ & $1.83 \pm 1.117$ & $2.67 \pm 1.470$ & $3.90 \pm 1.647$ & $<0.001^{*}$ \\
\hline $8 \mathrm{hrs}$ & $1.03 \pm 0.615$ & $1.57 \pm 0.774$ & $2.83 \pm 1.262$ & $<0.001^{*}$ \\
\hline $12 \mathrm{hrs}$ & $0.57 \pm 0.568$ & $0.70 \pm 0.702$ & $1.93 \pm 1.081$ & $<0.001^{*}$ \\
\hline $24 \mathrm{hrs}$ & $0.40 \pm 0.498$ & $0.53 \pm 0.507$ & $0.97 \pm 0.809$ & $0.002^{*}$ \\
\hline
\end{tabular}

Mean time to first rescue analgesia and percentage of patients who received tramadol as rescue analgesia, when compared among the groups showed statistically significant difference ( $\mathrm{p}$ value $<0.05)$ fig 1 and table 3 . 


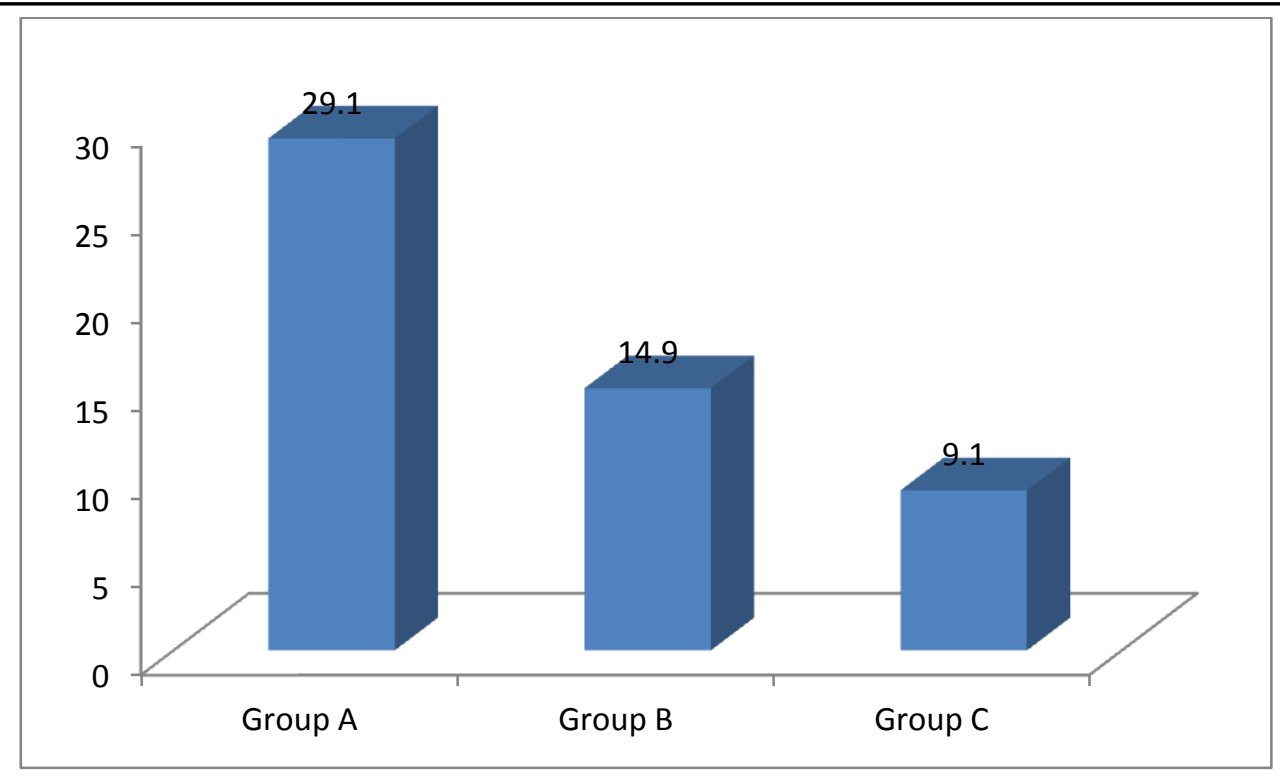

Fig 1

Table.3: Percentage of patients who received tramadol as rescue analgesia in each group.

\begin{tabular}{|c|c|c|c|c|c|c|c|}
\hline \multirow[t]{2}{*}{$\begin{array}{l}\text { Tramadol } \\
\text { Received }\end{array}$} & \multicolumn{2}{|c|}{$\begin{array}{c}\text { Group A } \\
\text { (Pregabalin) }\end{array}$} & \multicolumn{2}{|c|}{$\begin{array}{c}\text { Group B } \\
\text { (Gabapentin) }\end{array}$} & \multicolumn{2}{|c|}{$\begin{array}{c}\text { Group C } \\
\text { (Placebo) }\end{array}$} & $P$ value \\
\hline & No & $\%$ & No & $\%$ & No & $\%$ & \multirow{3}{*}{ P-value $=0.003 * * *$} \\
\hline Yes & 7 & 23.3 & 13 & 43.3 & 20 & 66.7 & \\
\hline No & 23 & 76.7 & 17 & 56.7 & 10 & 33.3 & \\
\hline
\end{tabular}

Post operative paracetamol (mg) consumption used within 24 hours had no significant difference between pregabalin and gabapentin groups.
However, the difference is statistically significant ( $\mathrm{p}$ value $<0.05$ ) when these two groups are compared to placebo group. Fig 2

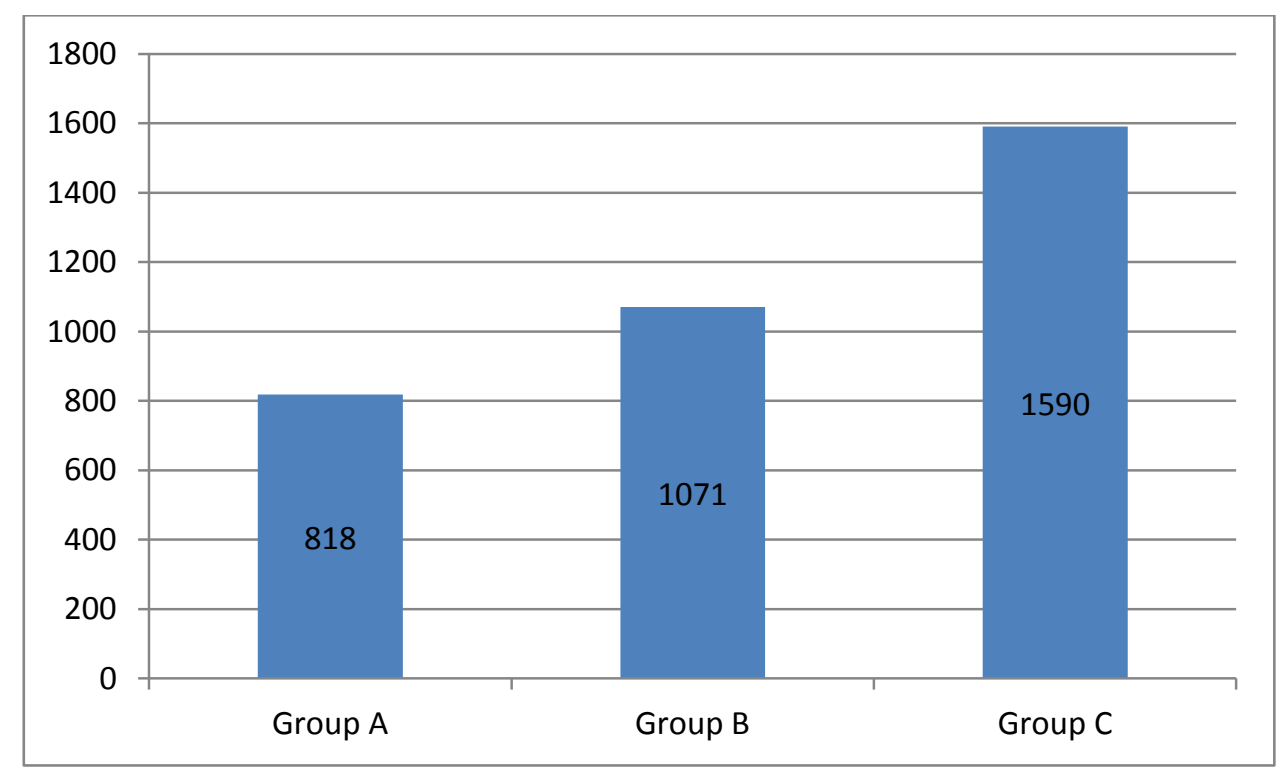

Fig 2

Post operative sedation scores using VAS at various time intervals show statistically significant difference among the three groups at $1 \mathrm{hr}, 4 \mathrm{hsr}$, 8hrs, 12hrs $(\mathrm{p}<0.05)$. However, there is insignificant difference among the three groups at $24 \mathrm{hrs}$ postoperatively ( $\mathrm{p}>0.05)$. Pregabalin group showed higher sedation scores among the three groups Fig 3 


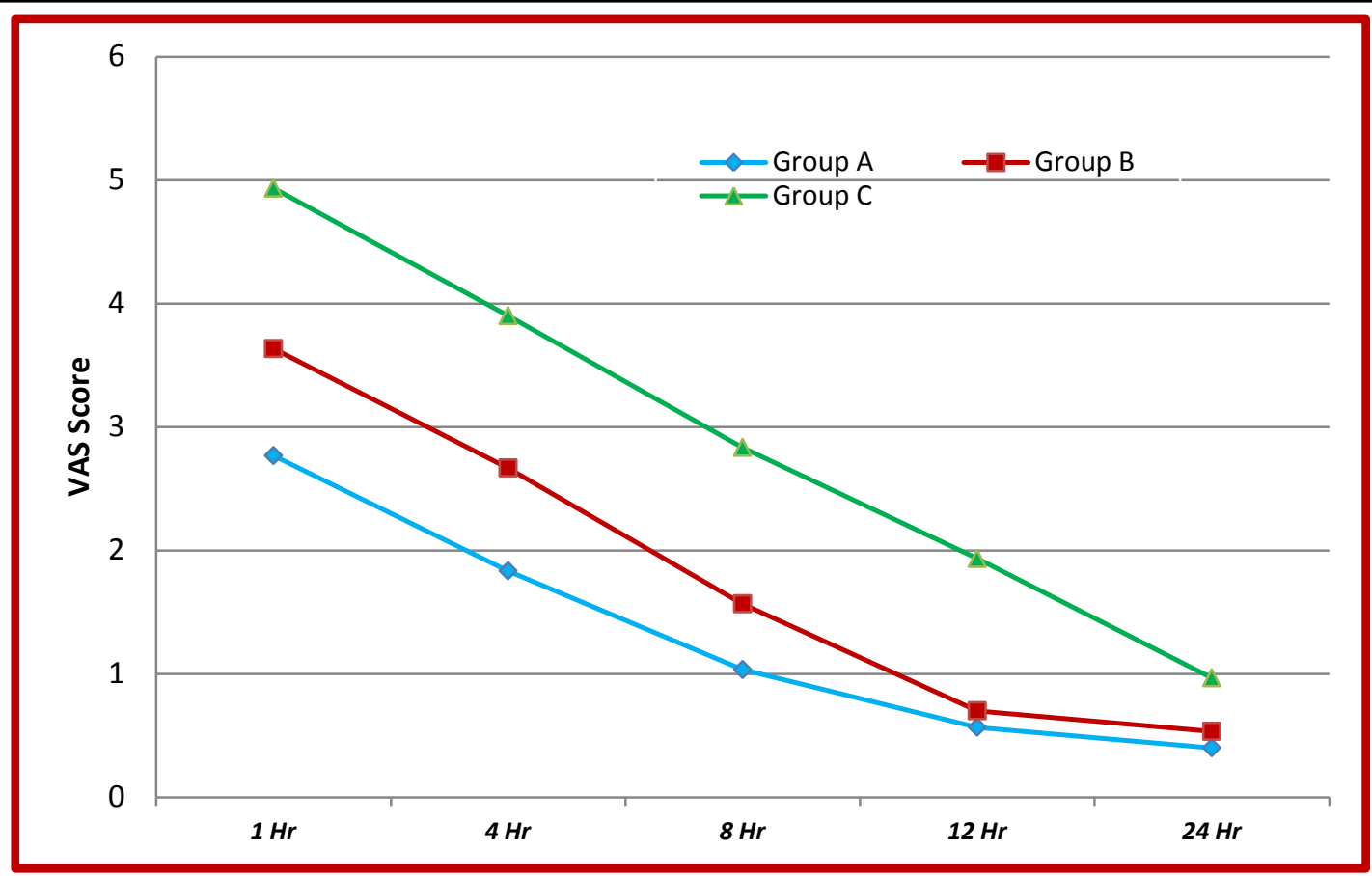

Fig 3

Table.4: Post operative complications among the study groups

\begin{tabular}{|l|c|c|c|c|}
\hline Variables & Group A & Group B & Group C & P value \\
\hline Nausea & $2(6.7 \%)$ & $2(6.7 \%)$ & $5(16.7 \%)$ & 0.308 \\
\hline Vomiting & $1(3.3 \%)$ & $2(6.7 \%)$ & $3(10 \%)$ & 0.574 \\
\hline Drowsiness & $15(50 \%)$ & $6(20 \%)$ & $0(0 \%)$ & $<0.001^{* *}$ \\
\hline Dizziness & $13(43.3 \%)$ & $5(16.7 \%)$ & $0(0 \%)$ & $<0.001^{* *}$ \\
\hline
\end{tabular}

The Incidence of PONV among the three groups was statistically insignificant. ( $p$ value>0.05). However, the incidence of drowsiness and dizzeness among the three groups is statistically significant $(\mathrm{p}<0.05)$. Pregabalin group has the highest incidence of drowsiness and dizzeness among the three groups (table4).

\section{Discussion}

Pre-emptive analgesia prevents the establishment of altered central processing of afferent input which amplifies postoperative pain. $^{5}$ It consequently decreases the incidence of hyperalgesia and allodynia after surgery. In our study we compared pre-emptive pregabalin with gabapentin for post operative analgesia in patients undergoing abdominal hysterectomy. The quality of analgesia was assessed using VAS at $1 \mathrm{hr}$, $4 \mathrm{hrs}$, $8 \mathrm{hrs}, 12 \mathrm{hrs}$, and $24 \mathrm{hrs}$ postoperatively and our results showed that there was statistically significant difference in mean VAS scores among the three groups $(\mathrm{P}<0.05)$. The quality of analgesia was better in Pregabalin group, followed by Gabapentin group. Our results are in concordance with the results of Pandey CK et al. who in their study found that Gabapentin group had significantly lower VAS scores at all time intervals than those in the placebo group. ${ }^{20}$ Agarwal et al. in their study found that a single preoperative oral dose of pregabalin $150 \mathrm{mg}$ is an effective method for reducing postoperative pain in patients undergoing laparoscopic cholecystectomy. ${ }^{21}$ In our study the mean time to first rescue analgesia (minutes) was compared among the three groups and found to be statistically significant ( $\mathrm{p}$ value $<0.05$ ). Rescue analgesia was used earliest in placebo group while time to first rescue analgesia was longest in pregabalin group. Thus using pregabalin and gabapentin preoperatively delayed the need for rescue analgesia. Our results are in accordance with the results of Pragati Arora Trivedi et al. who 
in their study found that Pregabalin is more effective than Gabapentin in prolongation of postspinal analgesia. ${ }^{22}$ In our study the percentage of patients who received tramadol as rescue analgesia was compared and this difference was statistically significant ( $\mathrm{p}$ value $<0.01$ ). Our results showed that Pregabalin group had the least requirement of rescue analgesia in PACU, followed by Gabapentin group, while the highest requirement was seen in Placebo group. Anju Ghai et al. in their study found that the difference in the consumption of diclofenac and tramadol between study groups (pregabalin and gabapentin group) and control groups was statistically significant $\quad(p>0.001){ }^{23}$ Similarly, Induja Rajendran et al. ${ }^{27}$ in their study found that consumption of tramadol as rescue analgesia was less in pregabalin and gabapentin groups compared to control and this difference was statistically significant $(\mathrm{P}<0.001){ }^{24} \mathrm{We}$ compared the mean consumption of paracetamol (mg) and found that Pregabalin group had the least mean paracetamol (mg) consumption, followed by Gabapentin group. Our results are in accordance with the results of Michael G.F. Rorarius et al. who in their study found that preemptive Gabapentin reduced the need for additional postoperative pain treatment (PCA boluses of $50 \mathrm{mg}$ of fentanyl) by $40 \%$ during the first twenty postoperative hours. ${ }^{25}$ Dirks et al. who in their study concluded that a single dose of 200 $\mathrm{mg}$ oral Gabapentin administered preoperatively result in a 50\% reduction in postoperative morphine consumption 2 and 4 hour after radical mastectomy. ${ }^{26}$ Among the various side effects observed, the mean postoperative sedation scores were compared at various time intervals and the difference was statistically significant $(\mathrm{p}<0.05)$. We observed that Pregabalin was associated with increased sedation as compared to gabapentin. Our results are in concordance with PWH Peng et al. who in their study found that Gabapentin is associated with an increased incidence of sedation. ${ }^{27}$ Similarly, Chetna Jadeja et al. in their study concluded that a single dose of preoperative pregabalin is associated with increased sedation. ${ }^{28}$ In our study we observed a lower incidence of postoperative nausea and vomiting (PONV) in patients treated with gabapentinoids, however this was found to be statistically insignificant. This anti-emetic mechanism of gabapentinoids is unknown but it could possibly be due to the indirect opiod sparing effect or a direct effect on emetogenic tachykinin activity. Our results are in accordance with the results of A. Agarwal et al who in their study found that the incidence and severity of PONV and number of patients requiring antiemetics was similar among the study and control groups $(\mathrm{P}<0.05) .{ }^{29}$ In our study the percentage of patients who developed drowsiness and dizziness post operatively was compared and found to be statistically significant $(\mathrm{p}>0.05)$. We observed that both pregabalin and gabapentin were associated with significant drowsiness and dizziness. Our study is in accordance with the findings of Saraswat V et al. who in their study compared the efficacy of Gabapentin and Pregabalin and found that dizziness and somnolence were the only side effects noticed in both groups. ${ }^{30}$ Anju Ghai et al. in their study found that the incidence of somnolence was $40 \%$ in pregabalin group, $33.3 \%$ in gabapentin group and $3.3 \%$ in control group $(p=0.002){ }^{31}$

\section{References}

1. Morgan GE, Mikhail MS, Murray MJ. Pain Management. In: Clinical anaesthesiology.4th edition. New York: Lange Medical Books/ McGraw Hill. 2006; 4(18): 359-362.

2. Herley RW, Murphy JD, Wu CL. Acute Post-Operative Pain. In: Miller RD, Eriksson LI, Fleisher LA, Wiener-Kronish JP, CohenNH, YoungWL(ed). Miller's anesthesia. $8^{\text {th }}$ edition. Philadelphia, PA: Churchill Livingstone/Elsevier.2015; 2(98):2975.

3. Turan A, Karamanlioğlu B, Memiş D, Usar P, Pamukçu Z, Türe M. The analgesic effect of gabapentin after total 
abdominal hysterectomy. Anesth. Analg. 2004; 98(5): 1370-1373.

4. Kehlet H, Dahl JB Anaesthesia, surgery, and challenges in postoperative recovery. Lancet. 2003; 362:1921-1928.

5. Wilder-Smith OH. [Pre-emptive analgesia]. Anaesthesist. 1995;44 Suppl 3: S529-34.

6. Chouinard G, Beauclair L, Belanger MC. Gabapentin: long-term antianxiety and hypnotic effects in psychiatric patients with co morbid anxiety-related disorders. Can J Psychiatry. 1998; 43(3):305.

7. Pitkänen A, Schwartzkroin P, Moshé S. In: Models of Seizures and Epilepsy. Burlington: Elsevier. 2005: 539.

8. Backonja M, Beydoun A, Edwards KR, Schwartz SL, Fonseca V, Hes $M$. Gabapentin for the symptomatic treatment of painful neuropathy in patients with diabetes mellitus: a randomized controlled trial. JAMA. 1998; 280(21): 1831-6.

9. Donovan-Rodriguez $\mathrm{T}$, Dickenson $\mathrm{AH}$, Urch CE. Gabapentin normalizes spinal neuronal responses that correlate with behavior in a rat model of cancer-induced bone pain. Anesthesiology. 2005; 102 (1): 132-40.

10. Gottrup H, Juhl G, Kristensen AD, Lai R, Chizh BA, Brown J, et al. Chronic oral gabapentin reduces elements of central sensitization in human experimental hyperalgaesia. Anesthesiology.2004; 101(6): 1400-8.

11. Hahn K, Arendt G, Braun JS, von Giesen HJ, Husstedt IW, Maschke $M$ et al. A placebo-controlled trial of gabapentin for painful HIV-associated sensory neuropathies. J Neurol. 2004; 251 (10): 1260-6.

12. Mellick LB, Mellick GA. Successful treatment of reflex sympathetic dystrophy with gabapentin. Am J Emerg Med.1995;13:96.
13. Nicholson B. Gabapentin use in neuropathic pain syndromes. Acta Neurol Scand. 2000; 101 (6): 359-71.

14. Rosenberg JM, Harrell C, Ristic H, Werner RA, de Rosayro AM. The effect of gabapentin on neuropathic pain. Clin J Pain.1997;13 (3): 251-5.

15. Rowbotham M, Harden N, Stacey B, Bernstein $\mathrm{P}$, Magnus-Miller L. Gabapentin for the treatment of postherpetic neuralgia: a randomized controlled trial. JAMA. 1998; 280 (21): 1837-42.

16. Werner MU, Perkins FM, Holte K, Pedersen JL, Kehlet $H$. Effects of gabapentin in acute inflammatory pain in humans. Reg Anesth Pain Med. 2001; 26 (4): $322-8$.

17. Lesser H, Sharma U, La Moreaux L, Poole RM. Pregabalin relieves symptoms of painful diabetic neuropathy:a randomized controlled trial. Neurology. 2004; 63(11): 2104-10.

18. Juns JH, Yaksh TL. The effect of intrathecal gabapentin and 3-isobutylgamma-aminobutyuric acid on the hyperalgesia observed after thermal injury in the rat. Anesth Analg.1998;86(2):34854.

19. Gupta A, Perniola A, Axelsson K, Thörn SE, Crafoord K, Rawal N. Postoperative Pain After Abdominal Hysterectomy: A Double-Blind Comparison Between Placebo and Local Anesthetic Infused Intraperitoneally. Anesth Analg. 2004; 99(4):1173-1179.

20. Pandey CK, Navkar DV, Giri PJ, Raza M, Behari S, Singh RB et al. Evaluation of the optimal preemptive dose of gabapentin for postoperative pain relief after lumbar diskectomy: A randomized, double-blind, placebo-controlled study. J Neurosurg Anesthesiol. 2005;17(2):65-8.

21. Agarwal A, Goutam S, Gupta D, Agarwal S, Singh PK, Singh U. Evaluation of single 
preoperative dose of pregabalin for attenuation of postoperative pain after laproscopic cholecystectomy. $\mathrm{Br} \quad \mathrm{J}$ Anaesth. 2008;101(5):700-4.

22. Trivedi PA, Mehta M, Trivedi J. Preemptive gabapentin versus pregabalin for post-operative analgesia after abdominal hysterectomy under spinal anaesthesia Int J Res Med. 2015; 4(1):53-58.

23. Ghai A, Gupta M, Hooda S, Singla D, Wadhera R: A randomized controlled trial to compare pregabalin with gabapentin for post-operative pain in abdominal hysterectomy. Saudi journal of anaesthesia. 2011; 5(3):252-7.

24. Rajendran I, Basavareddy A, Meher BR, Srinivasan S. Prospective, randomised, double blinded controlled trial of gabapentin and pregabalin as pre emptive analgesia in patients undergoing lower abdominal and limb surgery under spinal anaesthesia. Indian J Pain. 2014;28(3): 155-9.

25. Rorarius MF, Mennander S, Suominen P, Rintala S, Puura A, Pirhonen R et al. Gabapentin for the prevention of postoperative pain after vaginal hysterectomy. Pain. 2004;110(1-2):175-81.

26. Dirks J, Fredensborg BB, Christensen D, Fomsgaard JS, Flyger H, Dahl JB. A randomized study of effects of single dose gabapentin versus placebo on postoperative pain and morphine consumption after mastectomy. Anesthesiology. 2002;97(3):560-4.

27. Peng PW, Wijeysundera DN, Li CC. Use of gabapentin for perioperative pain control-a meta-analysis. Pain Res Manag. 2007;12(2):85-92.
28. Jadeja CA, Jadaliwala R, Kathiria M. Preemptive use of Gabapentin for postoperative pain relief in upper abdominal surgeries. Indian J Pain. 2014;28(2):99104.

29. Agarwal A, Goutam S, Gupta D, Agarwal S, Singh PK, Singh U. Evaluation of single preoperative dose of pregabalin for attenuation of postoperative pain after laproscopic cholecystectomy. $\mathrm{Br} \quad \mathrm{J}$ Anaesth. 2008;101(5):700-4.

30. Srivastava U, Kumar A, Saxena S, Mishra AR, Saraswat N, Mishra S. Effect of preoperative gabapentin on postoperative pain and tramadol consumption after minilap open cholecystectomy: a randomized double-blind, placebocontrolled trial. Eur. J. Anaesthesiol. 2010; 27(4): 331-335.

31. Ghai A, Gupta M, Hooda S, Singla D, Wadhera R: A randomized controlled trial to compare pregabalin with gabapentin for post-operative pain in abdominal hysterectomy. Saudi journal of anaesthesia. 2011; 5(3):252-7. 